\section{MS43-P11 Structure characterization of} lattice-matched rutile and $\mathrm{TiO}_{2}$-II phases grown by atomic layer deposition on

$$
\alpha-\mathrm{Al}_{2} \mathrm{O}_{3}\left(\begin{array}{lll}
0 & 0 & 1
\end{array}\right)
$$

Kristel Möldre ${ }^{1}$, Hugo Mändar ${ }^{1}$, Lauri Aarik ${ }^{1}$, Aivar Tarre ${ }^{1}$, Jaan Aarik $^{1}$

1. Institute of physics, University of Tartu, Ravila 14c, 50411, Tartu, Estonia

\section{email: kristel.moldre@ut.ee}

Atomic layer deposition of $\mathrm{TiO}_{2}$ from $\mathrm{TiCl}_{4}$ and ozone on single crystal $\alpha-\mathrm{Al}_{2} \mathrm{O}_{3}\left(\begin{array}{lll}0 & 0 & 1\end{array}\right)$ substrates was investigated. The structure of films was characterized using X-ray reflection (XRR) and X-ray diffraction (XRD) in high resolution (HR), in-plane (IP) and reciprocal space mapping (RSM) modes.

HR-XRD $\theta-2 \theta$ diffraction patterns of the films deposited on c-sapphire at $400-600^{\circ} \mathrm{C}$, showed two reflections together with their Pendellsösung fringes, which implied that $\left(\begin{array}{lll}1 & 0 & 0\end{array}\right)$-oriented high-pressure $\mathrm{TiO}_{2}$-II or strained rutile was formed. X-ray crystallite sizes in direction of surface normal, determined from boardening analysis of the reflections were comparable to the film thicknesses (XRR) at $T_{G} \geq 400^{\circ} \mathrm{C}$.

IP-XRD analysis revealed that at $400-600^{\circ} \mathrm{C}$ both rutile and $\mathrm{TiO}_{2}$-II were epitaxially grown in the films with epitaxial relationships of $\left[\begin{array}{lll}0 & 1 & 0\end{array}\right]_{\mathrm{R}} / /\left[\begin{array}{lll}1 & 0 & 0\end{array}\right]_{\mathrm{S}}$ and $\left[\begin{array}{ll}0 & 0\end{array}\right.$ $1]_{\mathrm{R}} / /\left[\begin{array}{lll}1 & 2 & 0\end{array}\right]_{\mathrm{S}}$ for rutile and sapphire, and $\left[\begin{array}{lll}0 & 0 & \mathrm{~S}\end{array}\right]_{\mathrm{H}} / /\left[\begin{array}{lll}1 & 0 & 0\end{array}\right]_{\mathrm{S}}$ and $\left[\begin{array}{lll}0 & -1 & 0\end{array}\right]_{\mathrm{S}} / /\left[\begin{array}{lll}1 & 2 & 0\end{array}\right]_{\mathrm{S}}$ for TiO -II and sapphire. It is worth noting that the $\left(\begin{array}{llll}0 & 0 & 1\end{array}\right)_{\mathrm{II}} / /\left(\begin{array}{lll}0 & 1 & 0\end{array}\right)_{\mathrm{R}}$ in-plane relationship for rutile and $\mathrm{TiO}_{2}-\mathrm{II}$ in our films differed from the $\left(\begin{array}{lll}0 & 0\end{array}\right.$ 1) $/ /\left\{\begin{array}{lll}0 & 1 & 1\end{array}\right\}_{\mathrm{R}}$ relationship reported earlier for $\mathrm{TiO}_{2}-\mathrm{II}$ and rutile in a natural form of $\mathrm{TiO}_{2}[1]$.

Lattice parameters were determined by IP-XRD analysis of reflections 020,002 of $\mathrm{TiO}_{2}-\mathrm{II}$ and 011 of rutile and by RSM of reflection 311 of $\mathrm{TiO}_{2}$-II and reflections 310 and 301 of rutile. The parameters of $\mathrm{TiO}_{2}$-II were $a_{I I}=0.4531 \pm 0.0002 \mathrm{~nm}, b_{I I}=0.546 \pm$ $0.003 \mathrm{~nm}$ and $c_{I I}=0.482 \pm 0.006 \mathrm{~nm}$ while those of rutile equaled to $a_{R}=0.4531 \pm 0.0002 \mathrm{~nm}, b_{R}=0.475 \pm 0.006$ $\mathrm{nm}$ and $c_{R}=0.29 \pm 0.01 \mathrm{~nm}$. According to these results the crystallites with $\mathrm{TiO}_{2}$-II and highly strained rutile structures were evidently lattice-matched to each other in the films. Comparison of the in-plane atomic arrangements in 2D unit cells of $\alpha-\mathrm{Al}_{2} \mathrm{O}_{3}\left(\begin{array}{lll}0 & 0 & 1\end{array}\right)$, rutile (1 $\left.\begin{array}{lll}0 & 0\end{array}\right)$ and $\mathrm{TiO}_{2}$-II ( $\left(\begin{array}{lll}1 & 0 & 0\end{array}\right)$ (Fig. 1) demonstrated relatively good lattice match explaining the epitaxial growth observed in our experiments.

From boardening analysis of reflections 110 and 111 for $\mathrm{TiO}_{2}-\mathrm{II}$ and $110,101,301$ for rutile the in-plane $\mathrm{X}$-ray crystallite sizes were estimated to be $4.0 \mathrm{~nm}$ for $\mathrm{TiO}_{2}$-II and $3.6 \mathrm{~nm}$ for rutile.

[1] D.W. Meng, X.L. Wu, F. Sun, L.W. Huang, F. Liu, Y.J. Han, J.P. Zheng, X. Meng, R. Mason, High-pressure polymorphic transformation of rutile to $\alpha-\mathrm{PbO}_{2}$-type $\mathrm{TiO}_{2}$ at $\left\{\begin{array}{lll}0 & 1 & 1\end{array}\right\}_{\mathrm{R}}$ twin boundaries, Micron 39 (2008) 280-286.

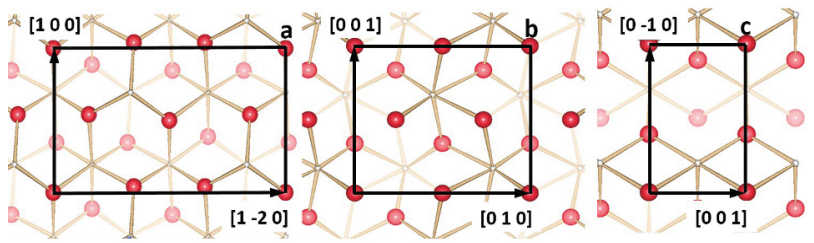

Figure 1. Structure models of in-plane unit cells and atomic arrangements for (a) $\alpha-\mathrm{Al}_{2} \mathrm{O}_{3}\left(\begin{array}{lll}0 & 0 & 1\end{array}\right)$, (b) $\mathrm{TiO}-\mathrm{II}\left(\begin{array}{lll}1 & 0 & 0\end{array}\right)$ and (c) rutile $\left(\begin{array}{lll}1 & 0 & 0\end{array}\right)$ atomic planes. Large spheres designate positions of oxygen and small spheres show location of Al or Ti. Labels at arrows show crystallographic directions.

Keywords: Titanium Dioxide, Thin Films, Atomic Layer Deposition, Crystal Structure, Epitaxy, TiO2-II, Rutile 